\title{
MutT homolog 1 counteracts the effect of anti-neoplastic treatments in adult and pediatric glioblastoma cells
}

\author{
Ziv Versano ${ }^{1,2, *}$, Eitan Shany ${ }^{1}$, Shany Freedman ${ }^{1,2}$, Liron Tuval-Kochen ${ }^{1,2}$, Moshe \\ Leitner $^{1}$, Shoshana Paglin ${ }^{1, * *}$, Amos Toren ${ }^{1,2, * *}$ and Michal Yalon ${ }^{1,3, * *}$ \\ ${ }^{1}$ Pediatric Hemato-Oncology, Edmond and Lilly Safra Children's Hospital and Cancer Research Center, Sheba Medical Center, \\ Ramat Gan 52621, Israel \\ ${ }^{2}$ Sackler School of Medicine, Tel Aviv University, Tel Aviv 69978, Israel \\ ${ }^{3}$ The Talpiot Medical Leadership Program, Chaim Sheba Medical Center, Ramat Gan 52621, Israel \\ *The work was performed in partial fulfillment of the requirements for the Ph.D. degree of Ziv Versano, Sackler School of \\ Medicine, Tel Aviv University \\ *** These authors have contributed equally to this work
}

Correspondence to: Michal Yalon, email: michal@droren.co.il

Keyword: MutT homolog 1; Nudix hydrolase; adult and pediatric glioblastoma; histone deacetyase inhibitors; PARP-1 inhibitors Received: November 16, $2017 \quad$ Accepted: May 19, $2018 \quad$ Published: June 08, 2018

Copyright: Versano et al. This is an open-access article distributed under the terms of the Creative Commons Attribution License 3.0 (CC BY 3.0), which permits unrestricted use, distribution, and reproduction in any medium, provided the original author and source are credited.

\section{ABSTRACT}

Glioblastoma, a fatal disease in both adult and pediatric patients, currently has limited treatment options that offer no more than temporary relief. Our experiments with adult and pediatric glioblastoma cell lines showed that radiation induces a dose-dependent increase in the level of MutT homolog 1 (MTH1) - an enzyme that hydrolyzes oxidized purine nucleoside triphosphates. Similarly, the combination of vorinostat, which is a histone deacetylase inhibitor, and ABT-888, which is a PARP-1 inhibitor, enhanced clonogenic death and increased the MTH1 level, relative to each treatment alone. This result suggests that the MTH1 level is directly related to the damage that is inflicted upon the cells, and its activity protects them against antineoplastic therapy. Indeed, the MTH1 inhibitor TH588 and MTH1 siRNA increased glioblastoma's response to both radiation and the combination of vorinostat and ABT-888. TH588 also inhibited glioblastoma's capacity for migration and invasion. In normal fibroblasts, low radiation doses and the combination of vorinostat and ABT888 decreased the level of the enzyme. TH588 did not alter the fibroblasts' response to radiation and only mildly affected their response to the combination of vorinostat and ABT-888.

In summary, the inhibition of MTH1 is required to better realize the therapeutic potential of anti-neoplastic treatments in glioblastoma.

\section{INTRODUCTION}

Glioblastoma is the most severe type of human brain tumor in both adults and children, with a median survival of 14.6 months for adults [1] and 13-18 months for pediatric patients $[2,3]$. The current standard treatment for adult glioblastoma consists of the sequential introduction of three modalities: a maximal-safe surgical resection, followed by radiotherapy in combination with temozolomide [1]. In contrast to adults, a significant percentage of pediatric patients' glioblastoma are located in the midline region of the brain and either, like diffuse intrinsic pontine glioma (DIPG), are completely inaccessible for surgical resection or, like the diffuse thalamic midline gliomas, are not favorably recommended for it. In pediatric patients, the addition of temozolomide failed to show any survival benefit compared to radiation therapy alone $[4,5]$. 
The lack of effective treatments for glioblastoma patients has led to a continuing search for new therapies. In particular, a great effort has been directed toward understanding the molecular characteristics of glioblastoma, which could provide clues to the disease's etiology and point to new molecular targets for drug development. Thus, genome analysis of tumors from primarily pediatric glioblastomas [6-8] as well as adult glioblastomas [9] revealed the existence of somatic heterozygous histone mutations that are mutually exclusive (i.e., different subtypes of glioblastoma that originate in different regions of the brain are associated with different specific mutations). Therefore, the $\mathrm{H} 3.3 \mathrm{~K} 27 \mathrm{M}$ and H3.1K27M mutations are associated with DIPG and other midline gliomas, while the H3.3G34R/V mutation has been found in hemispheric gliomas [10-12]. The K27M mutation leads to increased activity of both chromatin domains that suppress differentiation and of those that support proliferation. Notably, both types are essential for tumor survival [13-15].

In addition to molecular studies, the screening of chemical libraries and anti-cancer drugs aimed at the discovery of potentially effective treatments has also been conducted. In one such study, Funato et al. [16] revealed that the inhibitor of menin - a member of the trithorax family histone methyltransferase complex - inhibited the growth of human DIPG cells both in vitro and, in the xeongraft model, in vivo. Grasso et al. [17] demonstrated the inhibitory effect of panobinostat, which is the histone deacetylase inhibitor (HDACi), on the growth of DIPG human cell lines both in vitro and, in the tumor xenograft model, in vivo. In addition, van Vuurden et al. showed that the PARP-1 inhibitor (PARPi) olaparib sensitized pediatric high grade glioma to ionizing radiation [18]. The findings that histone deacetylase inhibitors sensitize breast, ovarian, prostate, and myeloid leukemia cancer cells to treatment with PARP-1 inhibitors, regardless of their innate capacity for repair of dsDNA breaks [19-22], are relevant to these studies. Our work, which focused on breast cancer cells that are inherently resistant to PARP-1 inhibitors, showed that vorinostat sensitized them to the inhibition of PARP-1 [20].

Similar to ionizing radiation and chemotherapy, HDACis lead to increased levels of reactive oxygen species (ROS), which participate in mediating their toxic effect [23-25]. Increased levels of ROS lead to increased levels of 8-Oxo-dGTP in the cellular nucleotide pool, which can lead to increased mutations and/or futile base excision repair and cell death when they enter the DNA. Therefore, any cellular machinery that counteracts the effect of 8-oxo-dGTP is likely to diminish the effect of the ROS production by anti-neoplastic treatments. Indeed, the survival of cancer cells that maintain a high metabolic rate relative to normal cells are dependent on the activity of the MTH1 enzyme, which prevents the incorporation of 8-oxo-dGTP into the DNA by hydrolyzing it into 8-oxo-
dGMP and pyrophosphate. Thus, it has been suggested that MTH1, which supports accelerated proliferation of cancer cells, may also block anti-cancer therapies [2629]. In addition to its effect on cancer cell survival and proliferation, recent studies have shown that abrogation of MTH1 expression in RAS-transformed lung cells decreased their capacity for migration [30].

In the present study, we show that, similar to what has been found with other human cancers [19-22, 31], the combination of HDACi and PARPi (vorinostat, a panHDACi, and ABT-888) increased clonogenic death in both pediatric and adult glioblastoma cell lines. Importantly, the combined treatment led to increased levels of ROS and of MTH1, relative to each treatment alone and to untreated cells. Inhibition of MTH1 activity in cells treated with both vorinostat and ABT-888 led to a further decrease in cell survival. These experiments also revealed that inhibition of MTH1 activity in-itself could increase the sensitivity of glioblastoma to treatment with PARP-1. Similarly, as noted by others $[32,33]$, ionizing radiation led to an increased level of MTH1. Again, the inhibition of MTH1 activity in irradiated cells enhanced their clonogenic death, relative to cells treated with radiation alone. The inhibition of MTH1 activity in normal fibroblasts did not alter their response to ionizing irradiation and had a milder effect on their response to the combination of vorinostat and ABT-888 than that observed in the glioblastoma cells. In addition, the inhibition of MTH1 activity in glioblastoma interferes with its capacity for cell migration and invasion

Our results suggest that, in glioblastoma, MTH1 activity serves as a defense mechanism against the cytotoxic effect of anti-neoplastic treatments. The activity of MTH1 should therefore be inhibited to better exploit the potential of the applied therapy.

\section{RESULTS}

\section{Combined treatment of vorinostat and ABT- 888 leads to enhanced clonogenic death in glioblastoma cell lines}

We have previously shown that vorinostat can sensitize human breast cancer cells to ABT-888, regardless of their BRCA status [20]. Here, we show that the combined treatment of vorinostat and ABT- 888 leads to increased clonogenic death of both pediatric and adult glioblastoma cell lines. The CI values point to a synergistic interaction of the drugs in KNS42. In U87, the interaction was additive at the lower concentration range and synergistic at the higher concentration range. (Figure 1). Increased levels of ROS are known to mediate the toxic effect of several anti-neoplastic treatments (23-25). However, under our experimental conditions and similar to what has been reported by others $[34,35]$, vorinostat and PARP-1 inhibitors had an opposite effect on the cellular level of ROS. While vorinostat increased the level of ROS, 
ABT-888 led to its decrease. Nonetheless, the combined administration of vorinostat and ABT-888 increased the fraction of cells with the highest ROS level relative to that obtained in controls, or in cells treated with vorinostat or PARP-1 inhibitor alone (Figure 2).

\section{The combination of vorinostat and ABT-888 increases the level of MTH1 in glioblastoma cell lines}

Cancer tissues are dependent on MTH1 activity for their survival due to their high levels of ROS [36, 37]. In addition, it has been demonstrated that ionizing radiation and kainate administration, which induce oxidative stress and elevate the level of ROS, lead to an increased cellular level of the MTH1 protein [23, 38]. As shown in Figure 3 , we determined the effect of vorinostat, ABT-888, and their combination on the level of MTH1 in KNS42, SF188, and normal fibroblasts. In KNS42 and SF188, the combined treatment of vorinostat and ABT- 888 led to an increased level of MTH1, relative to each one of the drugs. In contrast to glioblastoma, normal fibroblasts responded to the combined treatment by reducing the level of the enzyme. The increased level of MTH1 in treated cancer cells could potentially counteract the anti-neoplastic effect of the applied treatment. We therefore tested the effect of
MTH1 inhibitors on the survival of glioblastoma cell lines and normal fibroblasts.

\section{The effect of MTH1 inhibitors on the clonogenic survival of glioblastoma and normal fibroblasts}

We employed two different MTH1 inhibitors: TH588 and SCH51344. TH588 was developed by Gad et al. while SCH51344 was initially discovered through the screening of chemical libraries for inhibitors of RAStransformed cells, $[39,40]$, and later studies demonstrated that MTH1 is its cellular target [41]. As noted in Figure 4, KNS42 and SF 188 were sensitive to both inhibitors. SF188 cells, which carry a focal deletion of neurofibromatosis 1 at 17q11.2 [42], showed the highest sensitivity to TH588. This mutation leads to activation of RAS [43] and, like RAS-mutated cancer cells, may be extremely sensitive to MTH1 inhibition due to their high metabolic and ROS production rate [29]. The U87s were extremely sensitive to TH588 and less sensitive to SCH1344. Similarly, abrogation of MTH1 expression by two different MTH1 siRNA led to decreased survival of glioblastoma cells (Figure 5A, 5B). Normal fibroblasts responded poorly to both TH588 and SCH1344 (Figure 4). A similar effect of TH588 on the survival of glioblastoma cells has recently been demonstrated by Pudelko et al. [44].

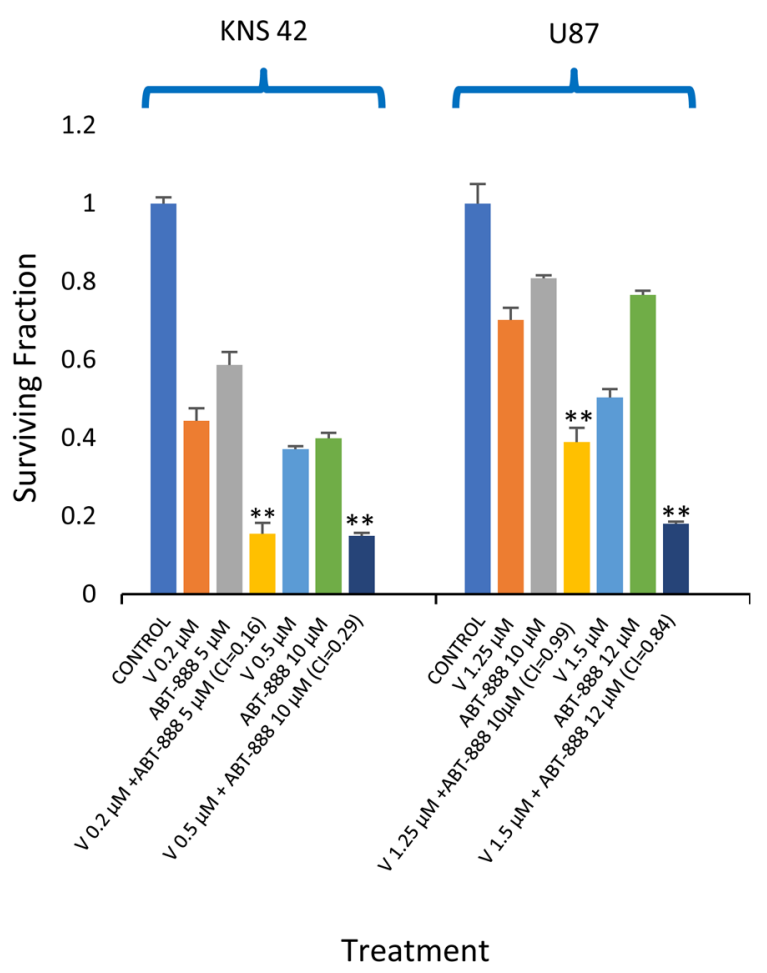

Figure 1: Vorinostat increases the sensitivity of glioblastoma to ABT-888: Colony survival assay and derivation of CI values was conducted as described in methods. Values are mean of surviving fraction \pm S.E.M of triplicates. Stars represent significant differences between the surviving fraction of the combination treatment and each one of its components. ${ }^{* *} \mathrm{p}<0.005$. 


\section{The effect of the MTH1 inhibitor on the cellular response to combined treatment of vorinostat and $\mathrm{ABT}-888$}

The fact that the combined treatment of vorinostat and ABT-888 leads to an increased level of MTH1, suggests that the activity of this enzyme may hamper the therapeutic potential of these drugs. The results shown in Figure 6 demonstrate that inhibition of MTH1 activity in cells treated with both vorinostat and ABT-888 does indeed increase their clonogenic death. In KNS42 and U87, the addition of TH588 to the combination of vorinostat and ABT- 888 reduced their clonogenic survival by half relative to the combination treatment and to TH588 alone. Similarly, MTH1 siRNA reduced clonogenic survival of KNS42 and increased their sensitivity to the combined treatment of vorinostat and ABT888 (Figure 5C). In fibroblasts, the addition of TH588 to the combination of vorinostat and ABT- 888 resulted in a milder $\sim 30 \%$ reduction in their clonogenic survival relative to the combination of vorinostat and ABT-888 (Figure 6).

\section{The MTH1 inhibitor increased sensitivity to the PARP-1 inhibitor in glioblastoma cell lines}

The experiment shown in Figure 6 suggests that TH588 can increase the response of glioblastoma to
PARP-1. Indeed, as noted in Figure 7, the inhibition of MTH1 activity increased the response of KNS42 to the PARP-1 inhibitor. The CI numbers indicate an additive interaction between the two drugs.

\section{Inhibition of MTH1 activity increases DNA damage caused by the combined treatment of vorinostat and $A B T-888$}

Increased phosphorylation of $\gamma-\mathrm{H} 2 \mathrm{AX}$ serves as an indicator for DNA damage [45]. As noted in Figure 8 , TH588 led to a dose-dependent increase of $\gamma$-H2AX. The level of $\gamma-\mathrm{H} 2 \mathrm{AX}$ in cells that were treated with the combination of the three drugs was higher than that detected following treatment with the combination of vorinsotat and ABT888 but similar to that obtained with $1.5 \mu \mathrm{M}$ TH588 alone. Importantly, while the combined treatment of vorinostat and ABT-888 led to only a moderate reduction in the cellular level of RAD51 addition of TH588 to this treatment led to a drastic reduction in the cellular level of the DNA repair protein. By itself TH5888 also led to a dose-dependent decrease of RAD51, albeit to a more moderate than that obtained by the three inhibitors combined. These results are in line with those obtained with the alkaline comet assay that employ hOGG1 in order to determine the effect of the various treatments on

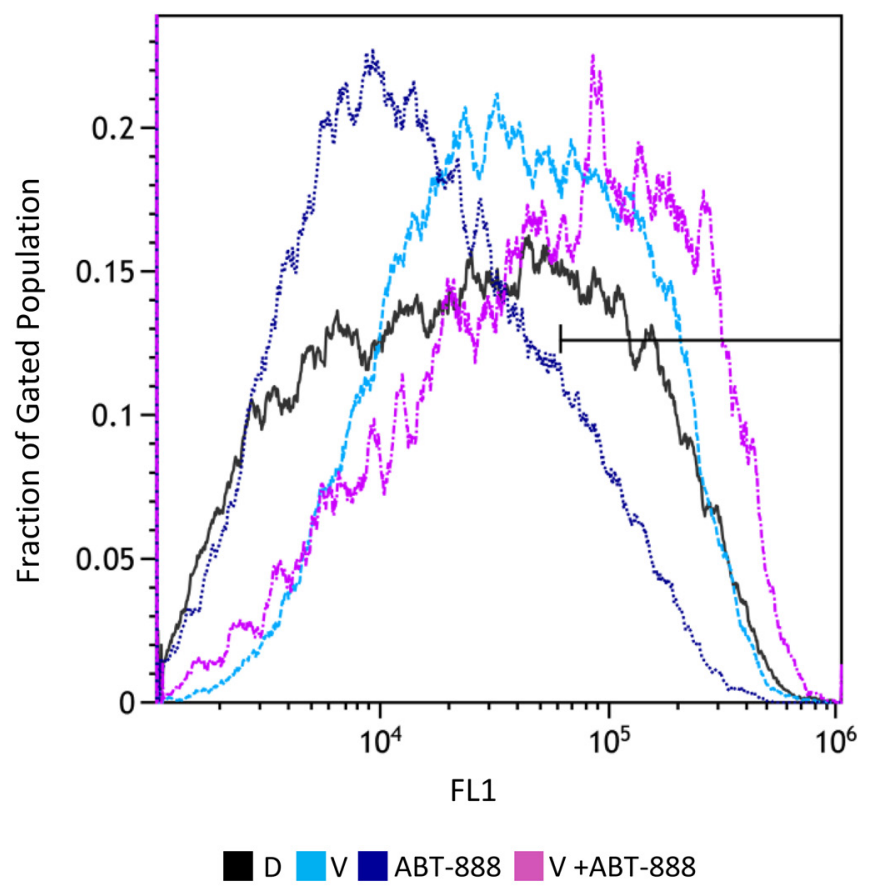

Figure 2: Combined treatment of vorinostat and ABT-888 increases cellular level of ROS: Cells were treated with 0.5 $\boldsymbol{\mu}$ M vorinostat (V), $10 \mu \mathrm{M}$ ABT-888 or both. Control untreated cells received DMSO (D). Seventy-two hours later, the cells were stained with $\mathrm{CM}-\mathrm{H}_{2}$ DCFDA and their ROS level was evaluated by flow-cytometry measurements of their fluorescent intensity as described in Methods. The bar indicates that the combination of vorinostat and ABT- 888 increases the fraction of cells with the highest fluorescent intensity (X-MED $\sim 6^{*} 10^{4}$ ) relative to cells treated with vorinostat or to controls. Treatment with ABT-888 leads to decreased level of ROS in the cells relative to control untreated cells. X-Med values for control, ABT-888 and vorinostat were $\sim 2.6^{*} 10^{4}, 1.3^{*} 10^{4}$, and $3.9^{*} 10^{4}$, respectively. 
the incorporation of 8-Oxo-dG into the DNA (Figures 9, 10). hOGG1 is a base excision repair protein that excises 8-Oxo-G when 8-Oxo-dG is incorporated opposite cytosine [46]. Its activity in the context of the comet assay increases the level of DNA breaks and therefore the fraction of cells with comets and the amount of DNA in the comets. We tested the effect of hOGG1 on the appearance of comets in cells treated with both vorinostat and ABT- 888 and in cells treated with the combination of vorinsotat, ABT-888 and TH588. While all treatment led to increased appearance of long comet relative to controls, there was no difference in the appearance of comets between vorinoatat and ABT- 888 or vorinostat, ABT- 888 and TH588 treated cells. Also, hOGG1 did not increase the appearance of comets in cells that were treated with vorinostat and ABT-888. However, a dramatic effect of hOGG1 on the appearance of comets was observed in cells that were treated with vorinostat, ABT-888 and TH588. Here an 11 fold increase in the appearance of comets relative to control was observed (Figure 10).

Interestingly, although the combination of vorinostat and ABT-888 increased the level of ROS in the cells, under our experimental conditions it did not lead to a significant increase in the incorporation of 8-Oxo-dG into the DNA, most probably due to elevated level of MTH1. However, inhibition of MTH1 activity in these cells resulted in a significant increase in the incorporation of 8-Oxo-dG into their DNA.

\section{The effect of MTH1 activity on the sensitivity to ionizing radiation}

As shown in Figure 11, radiation led to a dosedependent increase in the cellular level of MTH1 in the glioblastoma cell lines. Interestingly, in normal fibroblasts, treatment with 100, 150, and 200 rads decreased the level of MTH1, while 400 rads increased the cellular level of the enzyme. The addition of an MTH1 inhibitor to cancer cells, which had been irradiated with clinically relevant radiation doses [1, 4], led to increased clonogenic death, relative to each agent alone (Figure 12). Because SF188 cells are extremely sensitive to the inhibition of MTH1 (Figure $3)$, we employed low concentrations of TH588 (0.25 and $0.3 \mu \mathrm{M}$ ) in combination with extremely low doses of radiation (10 and 25 rads). Nonetheless, these combinations led to increased clonogenic death, which suggests that the inhibition of MTH1 may allow for the inclusion of a low radiation doses in clinical protocols for the treatment of pediatric glioblastoma with hyper-

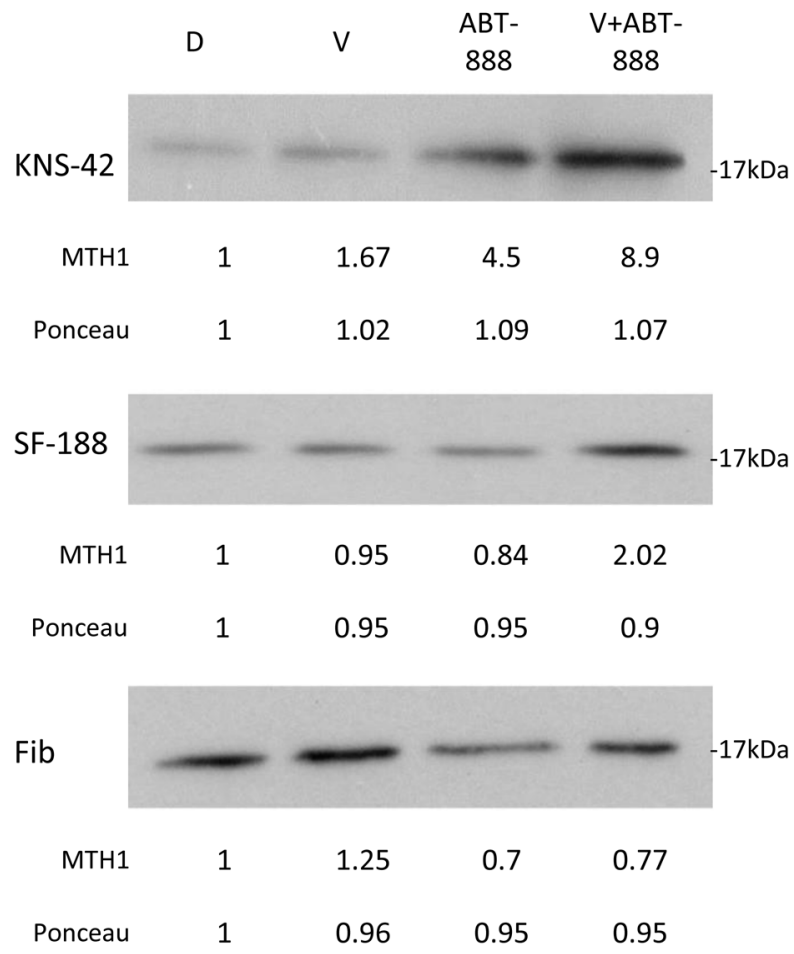

Figure 3: Combined treatment of vorinostat and ABT-888 increases cellular level of MTH1 in glioblastoma cells: Cells were treated with $0.5 \mu \mathrm{M}$ vorinostat $(\mathrm{V}), 10 \mu \mathrm{M}$ ABT-888 or both. Control untreated cells received DMSO (D). Fourty-eight hours later the cells were processed for Western blot analysis as described in Methods. Numbers at the bottom of the autoradiograms represent amounts of loaded proteins (ponceau) relative to control untreated cells and treatment-induced changes in the level of MTH1. Fib. - Fibroblasts. 
activated RAS. In KNS42 and U87 the nature of the interaction between the MTH1 inhibitor and the radiation was either additive at the lower concentration range or slightly synergistic at the higher concentration range. Here too, the results obtained with MTH1 siRNA were similar to those obtained with TH588. Abrogation of MTH1 expression increased the sensitivity of the cells to ionized irradiation (Figure 5D). The addition of TH588 to irradiated fibroblasts did not lead to a statistically significant increase in their clonogenic death. This result is in line with the fact that, under our experimental conditions, the radiation itself leads to a decreased level of the enzyme in normal fibroblasts (Figure 11).

\section{The effect of MTH1 activity on cell migration and invasion}

As noted in Figure 13, low concentrations of TH588, which do not affect the clonogenic survival of the cells, interfered with the KNS42 cells' capacity for cell migration and invasion.

\section{DISCUSSION}

Cancer cells maintain a higher metabolic rate than normal cells and therefore produce a higher level of ROS. High levels of ROS result in the harmful oxidation of cellular components, such as proteins, lipids, and
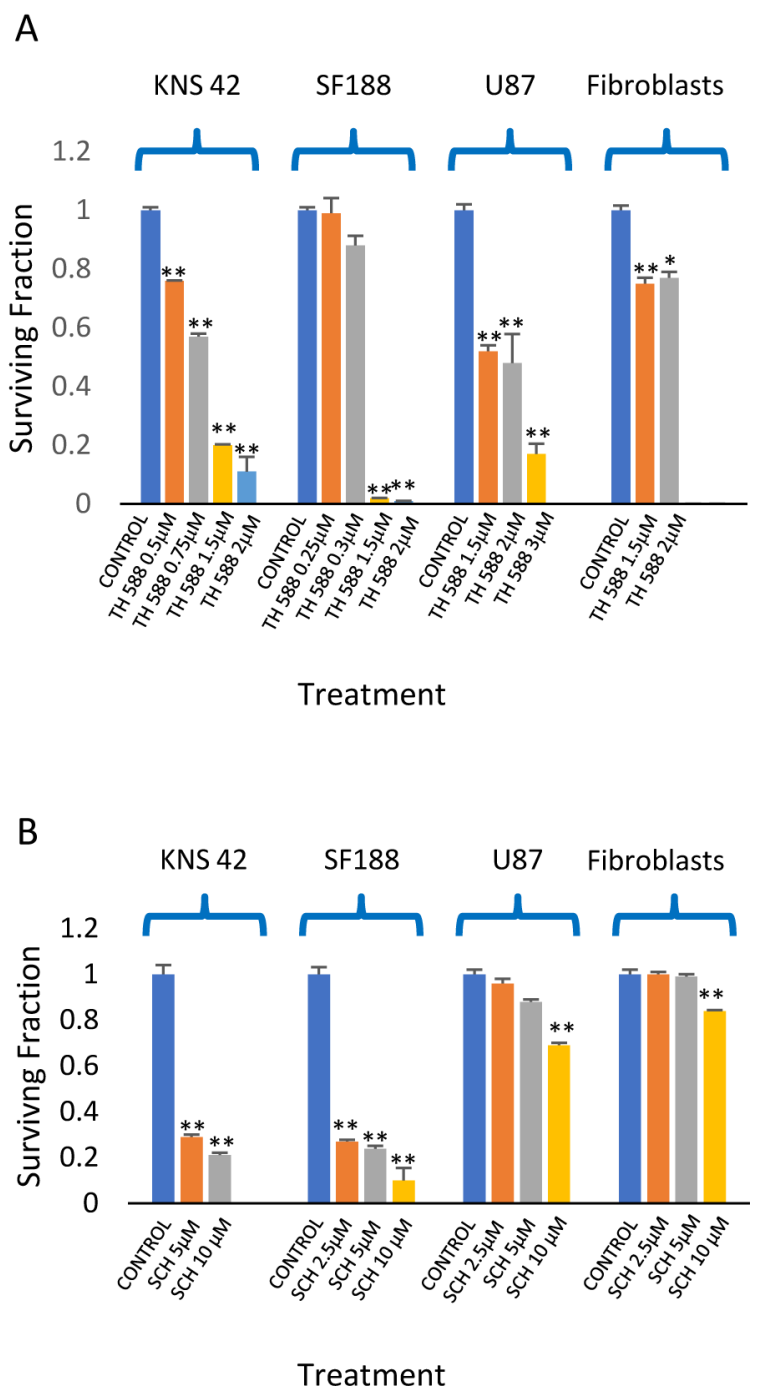

Figure 4: The effect of MTH1 inhibitors on the clonogenic survival of glioblastoma and fibroblasts: Colony survival assay was conducted as described in methods. Values are mean of surviving fraction \pm S.E.M of triplicates. (A) TH588. (B) $\mathrm{SCH} 5134$. The stars represent a significant difference between the surviving fractions of the treated cells and controls. ${ }^{*} \mathrm{p}<0.05,{ }^{* *} \mathrm{p}<0.005$. 
nucleotides [26, 29, 39]. Among the nucleotides in the soluble pool, dGTP and GTP are the most susceptible nucleotides to oxidation [26]. Gad et al. developed MTH1 inhibitors that inhibited the purified soluble enzyme as well as the intracellular enzyme in situ. The effect of TH588 on the accumulation of 8-Oxo-dG, on clonogenic survival and on tumor development was similar to that obtained following abrogation of MTH1 expression with specific RNAis [39, 47]. Notably, in human embryonic pulmonary fibroblasts, long-term abrogation of MTH1 expression by RNAi led to increased expression of 8-Oxoguanine (8-Oxo-G) DNA glycosylase 1 (OGG1) - an enzyme that could compensate for the loss of the MTH1 by removing 8-OxoG, which are found opposite to cytosine [48]. Thus, abrogation of MTH1 expression may

A
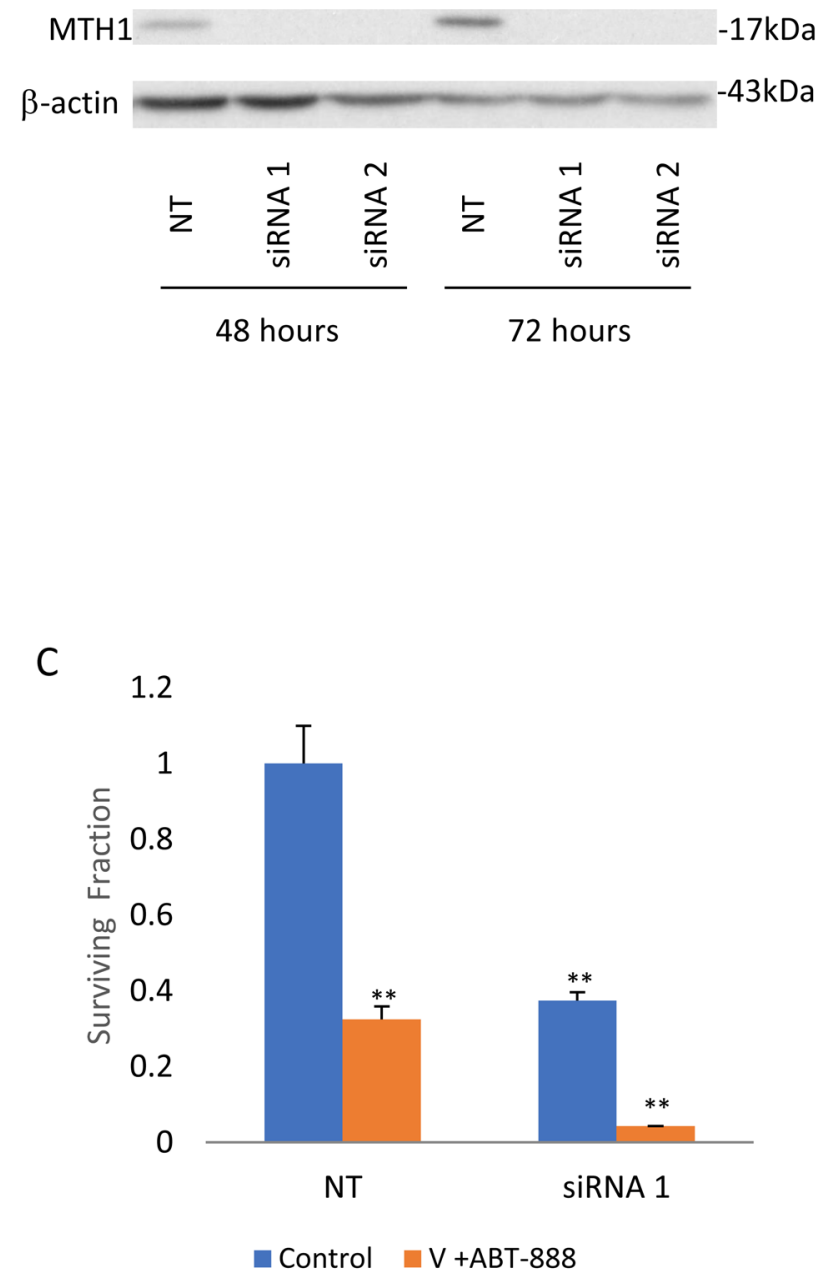

not always recapitulate the toxic effect of MTH1 inhibitors $[47,49]$.

Our studies evaluated the effect of MTH1 inhibitors and MTH1 siRNA on the sensitivity of glioblastoma to treatments with vorinostat and ABT-888 as well as to ionizing irradiation. The results showed that exposing glioblastoma to the combined treatment of vorinostat and ABT-888 led to increased clonogenic death. Interestingly, the combined treatment also led to an increase in the fraction of cells with the highest level of ROS and in the cellular level of MTH1, relative to each treatment alone. However, the increased level of MTH1 protein could not be triggered by increased ROS alone as a moderate increase in the level of MTH1 was observed in ABT-888 treated cells that showed a reduction in cellular level of

B

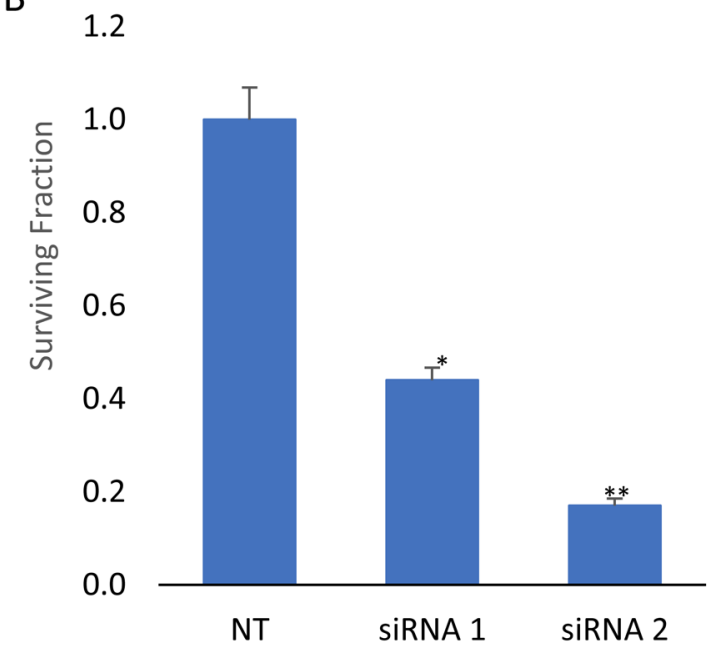

$\mathrm{D}$

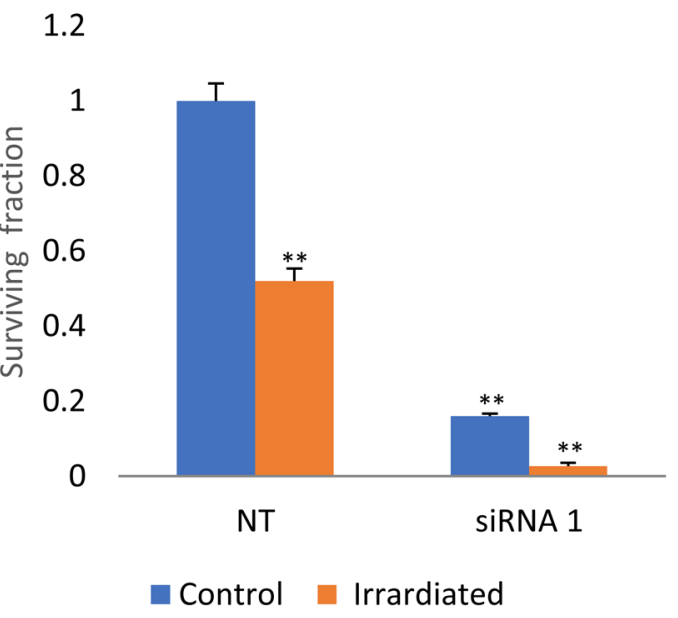

Figure 5: Abrogation of MTH1 expression decreases survival and increases sensitivity to combined treatment of vorinostat and ABT-888 and to ionizing irradiation: KNS-42 cells were transfected with MTH1 and control nontargeting (NT) siRMAs and processed for Western blot analysis or cell survival assays as described in methods. (A) Transfection with two different MTH1 siRNAs leads to decreased MTH1 expression by more than $80 \%$. Inhibition of MTH1 expression led to decreased cell survival (B) and to increased sensitivity to combined treatment of vorinostat and ABT-888 (C) or to ionizing radiation (D). Values are mean of surviving fraction \pm S.E.M of triplicates. ${ }^{*} \mathrm{p}<0.05,{ }^{* *} \mathrm{p}<0.005$. 
ROS. Nonetheless, the increased level of MTH1 following the co-administration of vorinostat and ABT- 888 prompted us to examine the possibility that the activity of MTH1 decreases the efficiency of this combined treatment. We first tested the effect of the MTH1 inhibitors TH588 and SCH51344 on the clonogenic survival of KNS42,

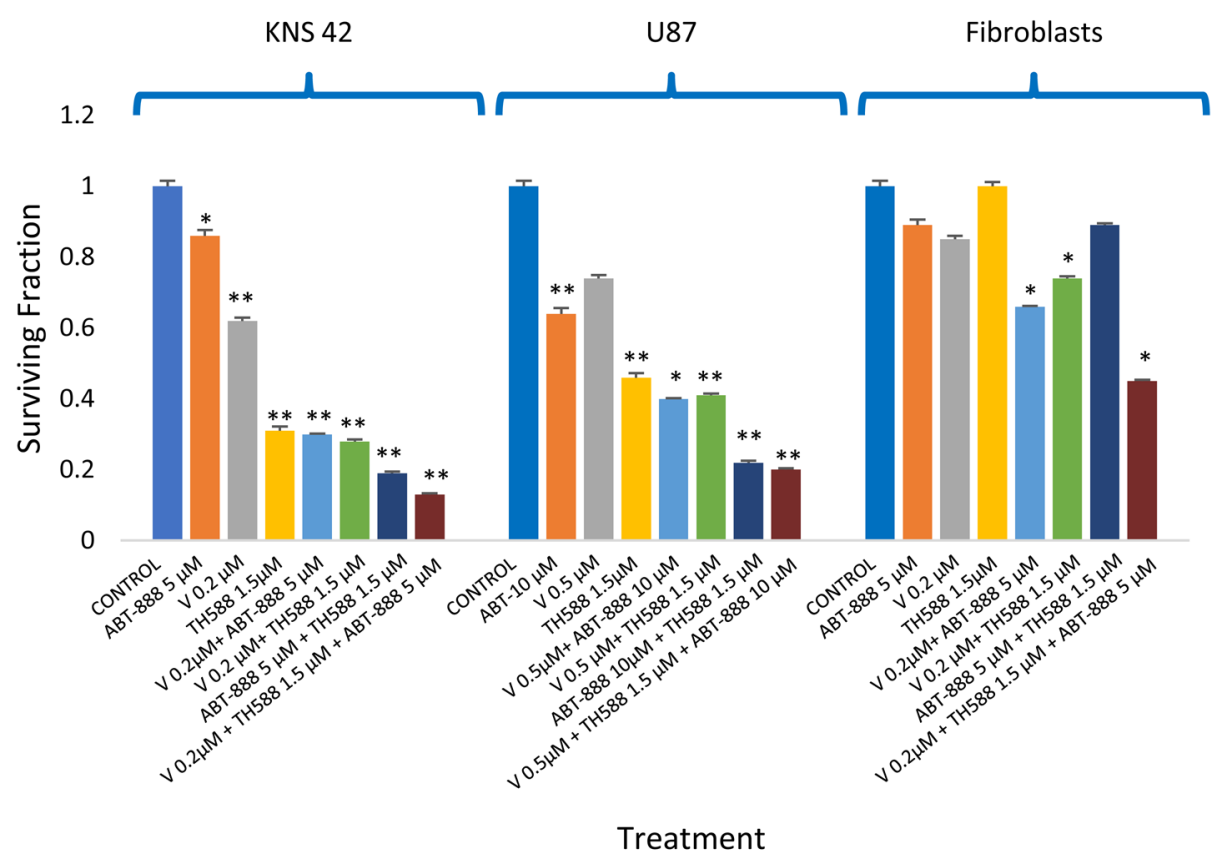

Figure 6: Inhibition of MTH1 increases the response of glioblastoma to the combination of vorinostat and ABT-888: Colony survival assay was conducted as described in methods. Values are mean of surviving fraction \pm S.E.M of triplicates. The stars represent significant differences between treatments with single agents and control, between combinations of two agents and each one of their components and between a combination of three agents and the combinations of TH588 and vorinostat, TH588 and ABT-888 and vorinostat and ABT-888. For U87 significance was similar to that observed in KNS42 except for the minor insignificant difference in survival between the triplicate and the combination of TH588 and ABT- 888 . ${ }^{*} \mathrm{p}<0.05,{ }^{* *} \mathrm{p}<0.005$.

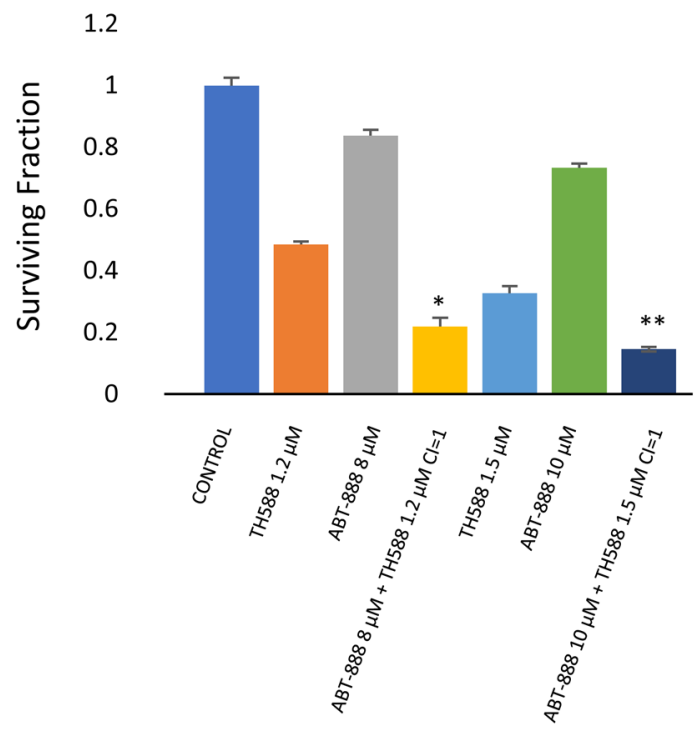

Treatment

Figure 7: MTH1 inhibitor increased sensitivity to PARP-1 inhibitor in KNS42: Colony survival assay and derivation of CI values was conducted as described in methods. Values are mean surviving fraction \pm S.E.M of triplicates. Stars represent significant differences between a combination treatment and each one of its components. ${ }^{*} \mathrm{p}<0.05,{ }^{* *} \mathrm{p}<0.005$. 
SF188, U87, and normal fibroblasts and found that the glioblastoma were sensitive to the inhibition of MTH1 activity, while normal fibroblasts were barely affected. As expected, the addition of TH588 to cancer cells treated with both vorinostat and ABT-888 further reduced their clonogenic survival by $50 \%$. In addition, the inhibition of MTH1 increased the response of cancer cells to the PARP1 inhibitor. It is possible that inhibition of the MTH1, which over time may result in the formation of ssDNA breaks, triggers the binding of PARP-1 as a prelude to the repair of those breaks. The inhibition of PARP-1 will inhibit the repair of ssDNA breaks and increase cell death. To the best of our knowledge, this mode of interaction between the inhibitors of PARP-1 and MTH1 has not been reported to date.

Our experiments showed that inhibition of MTH1 activity is associated with increased level of the DNA damage marker, $\gamma-\mathrm{H} 2 \mathrm{AX}$, and at the same time to a decreased level of the DNA repair protein, RAD51 and also increases the level of cyclin-dependent kinase inhibitor 1 ( p21) which leads to the arrest of cell cycle progression. In addition, under our experimental conditions, the comet experiments indicate that while the combined treatment of vorinostat and ABT- 888 induced DNA damage it did not lead to a detectable increase in 8-Oxo-dG in the DNA. In contrast, inclusion of TH588 in the combined treatment led to a dramatic increase in the DNA level of 8-Oxo-dG. This observation suggests that indeed increased level of MTH1 following administration of vorinostat and ABT-888 diminish the harmful effect of the applied treatment.

Recently, it has been demonstrated that ionizing radiation induced an increase in the level of both MTH1 mRNA and protein $[32,33]$. We also found that irradiation of cancer cells with $100,150,200$, and 400 rads led to an increased level of the MTH1 protein in cancer cells.

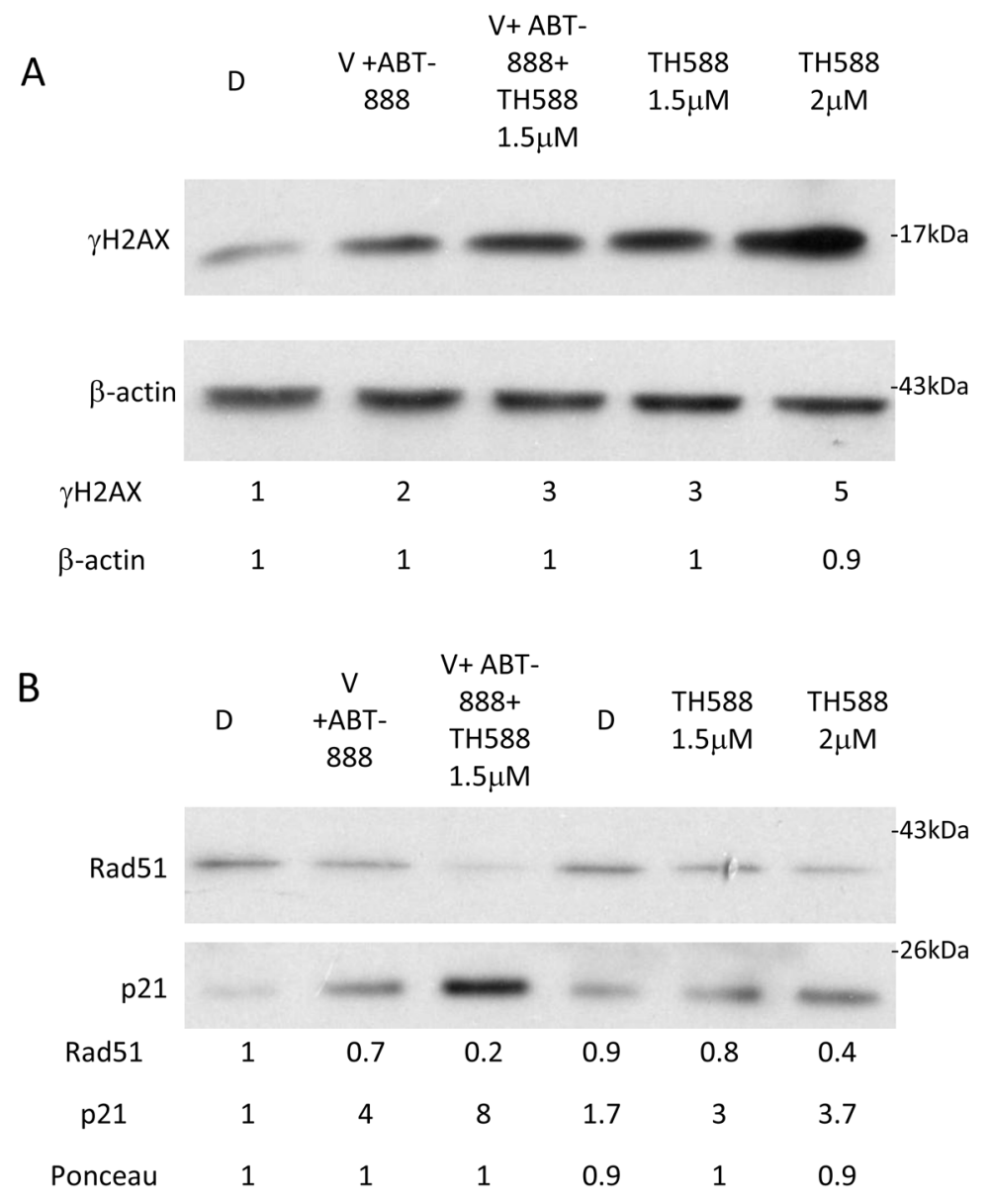

Figure 8: The effect of MTH1 activity on the level of $\gamma$-H2AX, RAD51 and p21 in cells treated with both vorinsotat and ABT-888: Cells were treated with the specified drugs for $\mathbf{4 8}$ hours and processed for Western blot analysis as described in methods. $\mathrm{V}(0.5 \mu \mathrm{M}$ vorinostat), ABT-888 $(10 \mu \mathrm{M})$, TH588 (1.5 $\mu \mathrm{M}$ in combination with V and ABT-888), (A) Numbers at the upper row represent treatment induced change in the level of $\gamma-\mathrm{H} 2 \mathrm{AX}$ relative to control and at the lower raw treatment induced change in the level of $\beta$-actin (loading control). (B) Numbers at the two upper rows represent treatment induced changes in the level of RAD51 and p21 and at the lower row the amounts of loaded proteins (ponceau) relative to control untreated cells. The p21 row is composed of two different experiments: 1. D, V+ABT-888, V+ABT-888+TH588 and 2. D, TH5881.5uM and TH5882uM 

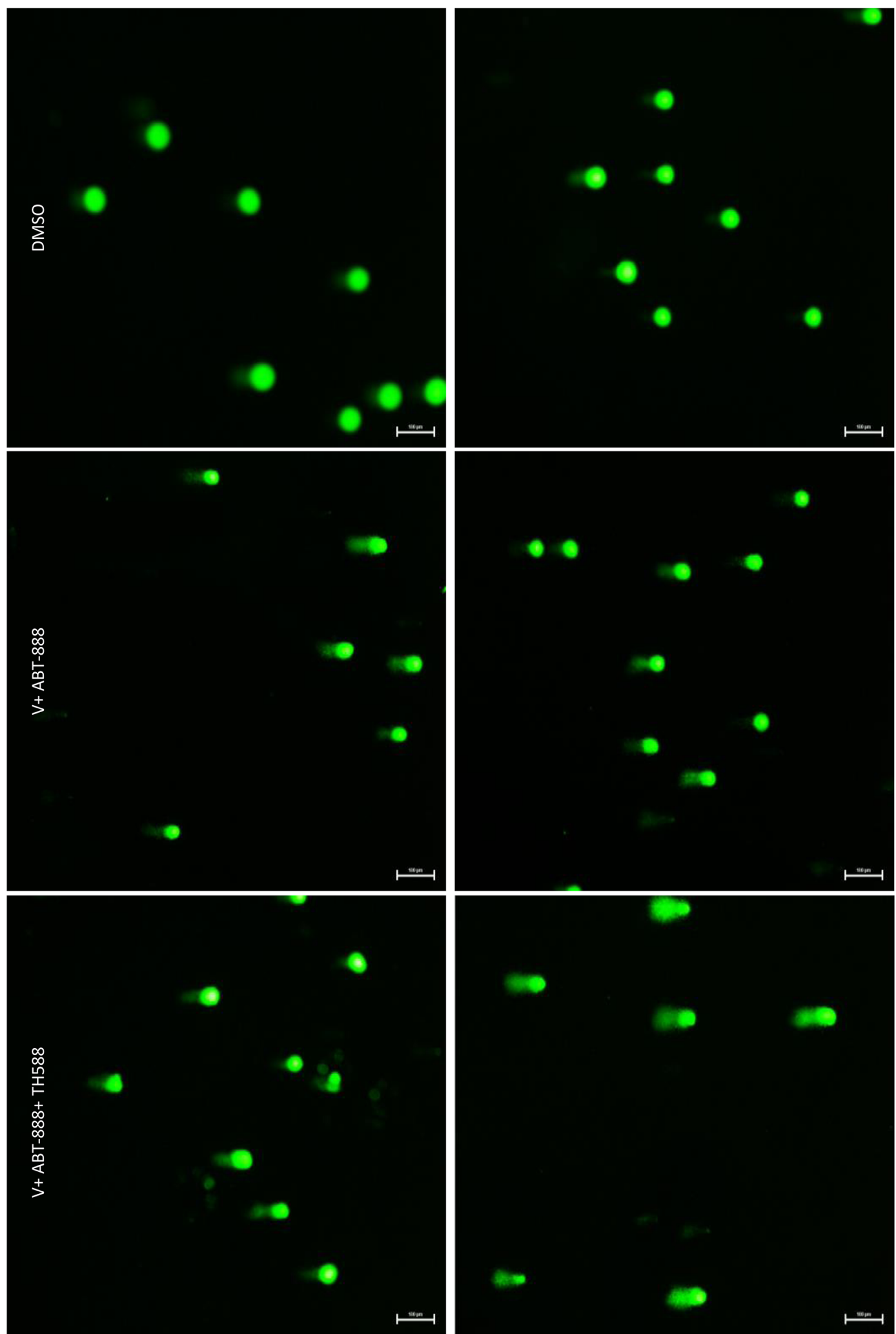

Figure 9: The effect of MTH1 on DNA damage in cells treated with both vorinostat and ABT-888: Cells were incubated with the specified drugs and the effect of hOGG1, on the results obtained with the comet assay were tested as described in methods. 


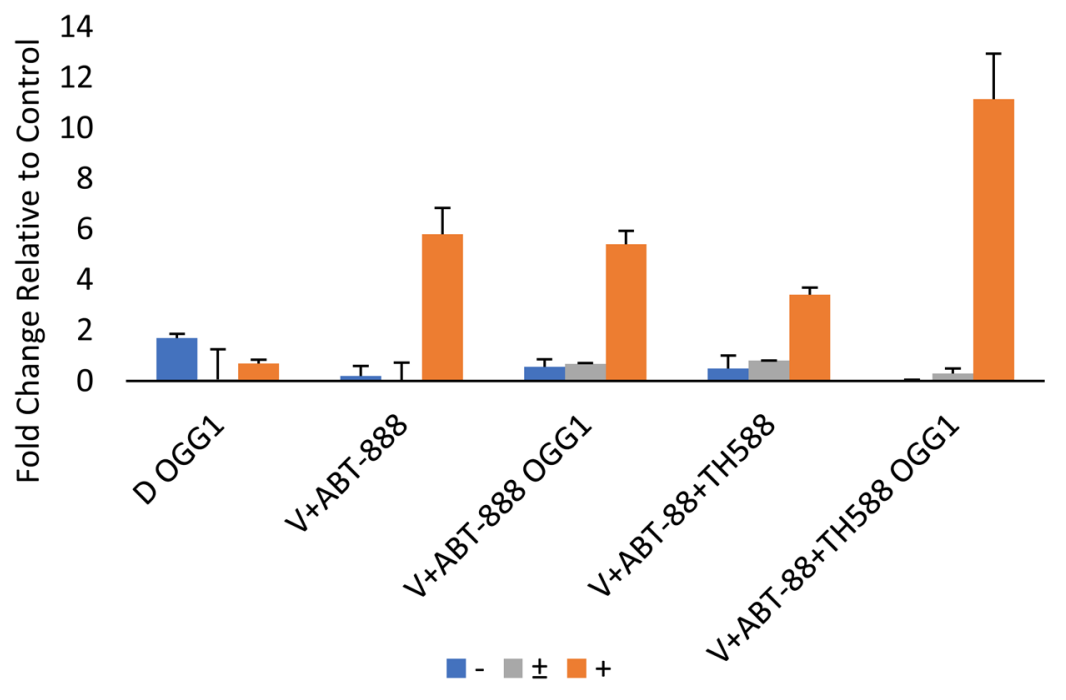

Figure 10: Quantification of the results obtained in the comet assay: Quantification was performed as described in methods. DMSO (D). V+ABT-888 (cells treated with vorinostat and ABT-888), V+ABT-888+TH588 (cells treated with vorinostat, ABT888 , and TH588). OGG1, Slides are treated with hOGG1(+) or with its vehicle OGG1 (-) before electrophoresis. Numbers are average \pm SEM of fold change relative to control from two independent experiments (100 comets were counted in each sample). Cells treated with $\mathrm{V}+\mathrm{ABT}-888+\mathrm{TH} 588+$ OGG1 displayed the highest fraction of cells with long comets.

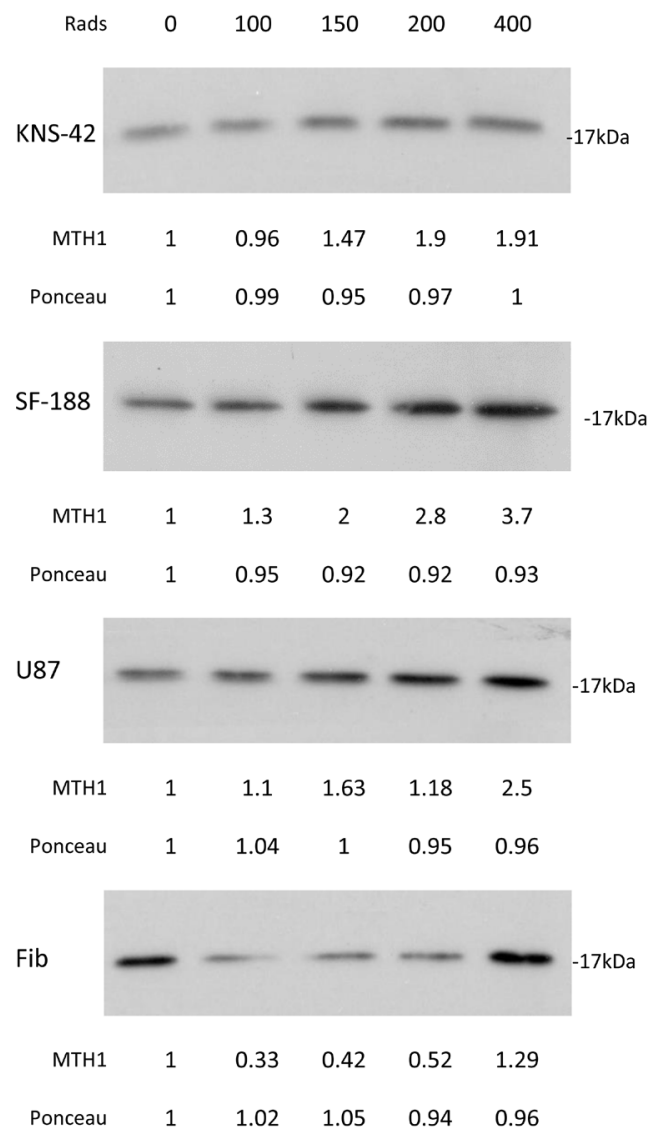

Figure 11: The effect of ionizing radiation on cellular level of MTH1 in glioblastoma and normal fibroblasts: Cells were irradiated and 48 hours later were processed for Western blot analysis as described in methods. Numbers at the bottom of the autoradiograms represent treatment-induced changes in the level of MTH1 and amounts of loaded proteins (ponceau) relative to control untreated cells. The experiment was reproduced once with similar results. 


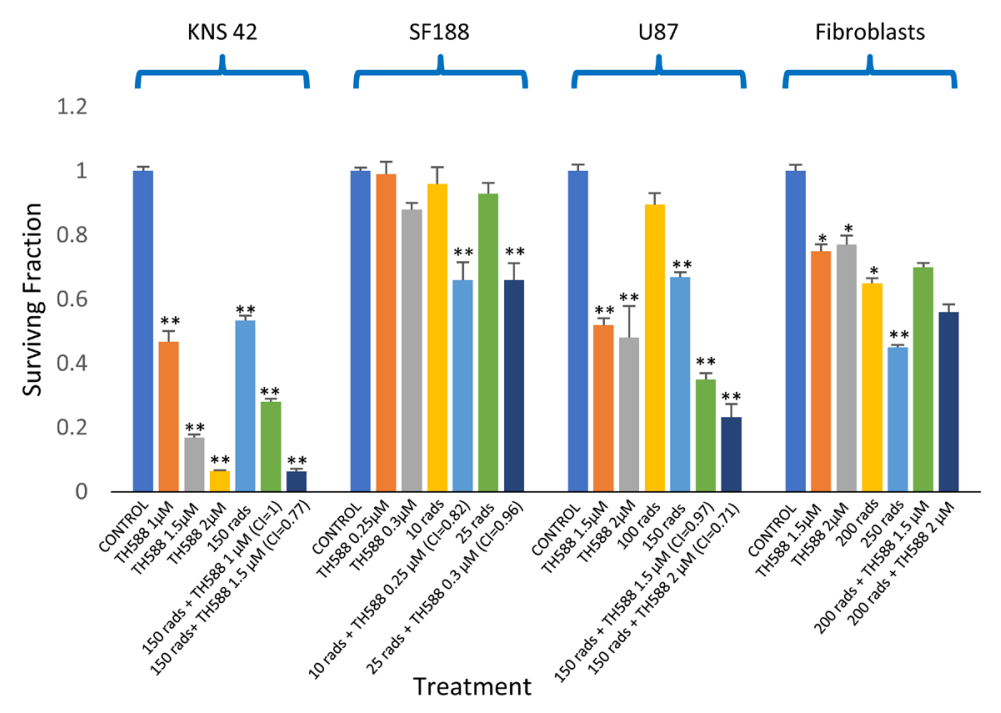

Figure 12: The effect MTH1 inhibitor - TH588 - on the sensitivity to ionizing irradiation of glioblastoma and fibroblasts: Cells were plated for colony survival assay and derivation of CI values were described in methods. Values are mean surviving fraction \pm S.E.M of triplicates. Stars represent significant differences between a single agent and control and between a combination treatment and each one of its components. Fib. - Fibroblasts. ${ }^{*} \mathbf{p}<\mathbf{0 . 0 5},{ }^{* *} \mathrm{p}<0.005$.

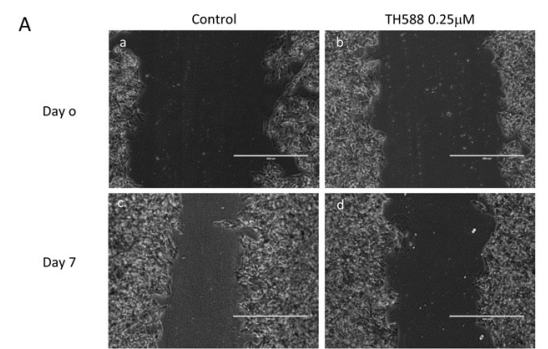

B

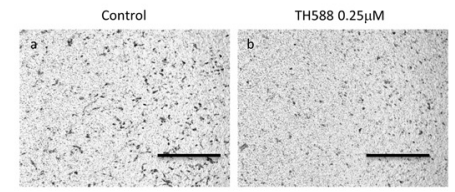

C
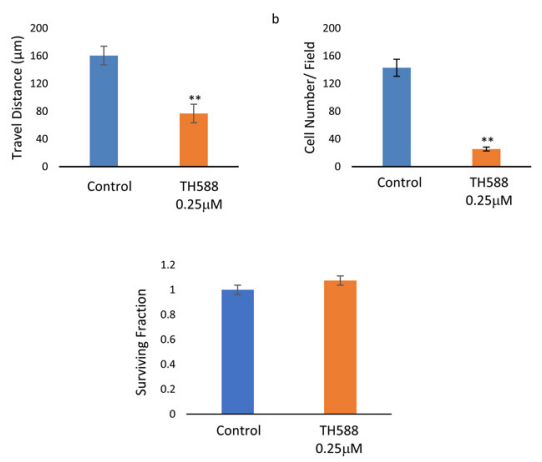

Figure 13: MTH1 inhibitor interferes with cell migration and invasion: (A) The inhibitory effect of TH588 on KNS42 migration was manifested in the wound-healing assay as a difference in the width of the scratch between control and TH588 treated cells. Control untreated cells at time 0 (a) and four days later (b). TH588 treated cells at time 0 (c) and four days later (d). Bar, $400 \mu \mathrm{M}$. (B) TH588 inhibits the capacity of KNS24 for invasion: Control (a,c) and TH588 treated cells (b,d). Bar, $100 \mu \mathrm{M}$. (C) The extent of TH588 inhibition of KNS42 migration (a) and invasion (b) are presented in the histograms. Differences between control and experimental was specific $\mathrm{p}<0.005$. Numbers are mean \pm S.E.M of the travelled distance in $\mu \mathrm{M}$ measured at 10 different fields (a) and of cells at the bottom side of the insert at the end of the experiment counted at 5 different fields (b). (D) TH588 at $0.25 \mu \mathrm{M}$ does not affect the clonogenic survival of KNS42. 
Curiously, radiation doses of 100, 150, and 200 rads led to a decreased level of MTH1 in normal fibroblasts, while 400 rads led to an increased level of the protein in these cells. The addition of MTH1 inhibitors to cancer cells following irradiation with clinically relevant doses (100-200 rads) led to increased clonogenic death of cancer cells, relative to radiation treatment alone. The interaction between the MTH1 inhibitor and radiation was either additive under the milder conditions or mildly synergistic under harsher conditions (i.e., higher concentrations of the MTH1 inhibitor and higher radiation doses). This result is of vital importance to pediatric glioblastoma patients, whose main treatment-option is ionizing radiation. An increased response to ionizing radiation in TH588-treated neuroendocrine tumor cell lines has recently been reported by Prada et al. [50]. In contrast to the glioblastoma cell lines, the MTH1 inhibitor failed to affect the clonogenic survival of irradiated fibroblasts.

Recent studies with breast cancer-expressing oncogenic RAS showed that abrogation of MTH1 expression led to both decreased expression of E-cadherin and suppression of the mesenchymal phenotype, which are both features that are associated with cancer cells' capacity for migration and invasion [29, 30]. Our results showed that low concentrations of TH588, which by themselves do not affect clonogenic survival, inhibited both cell migration and invasion.

It has been reported that that the activity of MTH1 protects the brain against oxidative damage [38]. Our studies demonstrated that inhibitors of MTH1 decrease clonogenic survival of glioblastoma cells and increase their response to therapy. This is of particular relevance to pediatric glioblastoma, where the addition of temozolomide to ionizing radiation does not result in delayed tumor progression. By contrast, in adult glioblastoma, the standard treatment is combined temozolomide and radiation. Therefore, localized inactivation of MTH1 activity, such as convectionenhanced delivery [17], may have to be developed. In addition, understanding the molecular mechanisms that underlie the increased level of MTH1 in treated glioblastoma may lead to the finding of cellular targets for the development of drugs that will specifically inhibit the expression of MTH1 in these tumors.

\section{MATERIALS AND METHODS}

\section{Cell lines}

Short, tandem, repeat profiling for authentication of U87, SF-188 and KNS42 was performed by the Genomic Center Core Facility (Technion, Haifa). The human glioblastoma cell line U87 from the American Type Culture Collection (Manassas, VA) was authenticated in 2014, and its frozen aliquots are being resuscitated and used for eight weeks. The SF188 cell line was kindly provided in 2014 by Dr. Daphne Haas-Kogan (UCSF, San Francisco, CA). This cell line was authenticated in 2017, and frozen aliquots were prepared and are being resuscitated and used for eight weeks. The pediatric KNS-42 cell line expressing H3.3G34V, which was authenticated by short, tandem, repeat profiling, was purchased in 2012 from the Japanese Collection of Research Bioresources Cell Bank(Osaka, Japan). Following a short propagation period, the cells were frozen, and aliquots were resuscitated and used for eight weeks. The cell line was re-authenticated again recently as mentioned above. Fibroblasts were obtained from dermal human fibroblasts, per protocol \#7044 (approved by the Institutional Review Board at Sheba Medical Center).

\section{Growth conditions}

U87 cells were grown in high-glucose Dulbecco's modified Eagle's medium (DMEM), KNS-42 cells were grown in Eagle's minimal essential medium, and SF188 cells were grown in high-glucose DMEM. The media were supplemented with fetal bovine serum (FBS) $(5 \%$ for KNS-42 and 10\% for SF188 and U87), penicillin, and streptomycin (Biological Industries, Kibbutz BeitHaemek, Israel). Fibroblasts were grown in high-glucose DMEM that was supplemented with $20 \%$ FBS, penicillinstreptomycin, $1 \%$ non-essential amino acids, and $0.2 \%$ $\beta$-mercaptoethanol (Invitrogen, Life Technologies, Grand Island, NY). For the Western blot analysis of cellular proteins, cells were plated at a density of $4.10^{3}$ per $\mathrm{cm}^{2}$, and treatment was initiated 48 hours post-plating. Drugs were added from stock solutions in dimethyl sulfoxide (DMSO) (Sigma, St. Louis MO), and the controls received the vehicle. The concentration of DMSO in the growth medium did not exceed $0.08 \%$. Crystallized trypsin was also from Biological Industries.

\section{Reagents}

Vorinostat was obtained from LC laboratories (Boston, MA), and the ABT-888 was from APExBIO (Houston, TX). The MTH1 inhibitors TH588 and SCH51344 were obtained from Sigma (St. Louis Mo) and Tocris Bioscience (Bristol, UK), respectively. hOGG1 FLARE ${ }^{\mathrm{TM}}$ assay kit was from Trevigen (Gaithersburg, MD), 5-(and-6)-chloromethyl-2',7'dichlorodihydrofluorescein diacetate, acetyl ester (CM$\mathrm{H}_{2}$ DCFDA) was obtained from ThermoFisher Scientific (Waltham, MA). SilencerR Select valudated siRNA and non-targeting (NT)-siRNA control were purchased from ambion (Carlsbad, CA) and Lipofectamine RNAiMAX reagent was from Invitrogen (Waltham, MA).

\section{Radiation}

Cells were irradiated in an X-ray irradiator (Polaris sc-500 series II) at a dose-rate of $100 \mathrm{cGy} /$ minute. 


\section{Clonogenic survival}

Plating for the colony survival assay, colony counting, and calculation of clonogenic surviving fraction was performed in triplicate, as described previously [51-53]. Treatments (radiation and addition of drugs) were performed 24 hours post-plating. Experimental combination indices $(\mathrm{CI})$ were obtained by employing the computer program CompuSyn, per Chou [53]. CI < 1 indicated synergistic interaction, and $\mathrm{C}=1$ indicated an additive one (Chou TC [53]). All experiments were reproduced at least once. To determine the effect of MTH1 siRNA on cell survival and sensitivity to treatment we employed the following MTH1 siRNAs (Sense sequences: \#1. CGACGACAGCUACUGGUUtt \#2. CA UCUGGAAUUAACUGGAtt).

For evaluating inhibition of MTH1 expression cells were processed for Western blot analysis as described below. For evaluating the effect of MTH siRNAs on cells' viability, the cells were seeded in 24 well plates $(10,000 /$ well) and transfection with $5 \mathrm{nM}$ MTH1 siRNAs and control non-targeting siRNA was carried out 24 hours later with lipofectamine RNAiMAX reagent according to the manufacturer's instructions. The cells were incubated for five additional days, and then removed by trypsinization mixed with trypan blue for counting of live cells. The effect of siRNA on the sensitivity of the cells to ionizing irradiation or to the combined treatment of vorinostat and ABT-888 was conducted as follows: Cells were seeded in 6 well plates $(200,000 /$ well $)$ and transfected with $10 \mathrm{nM}$ siRNA 24 hours later. The cells were then incubated for additional 72 hours. At that time the cells were harvested and seeded in a 6-well dish (500/well). Radiation or addition of drugs was conducted 24 hours post seeding and incubation was continued for 10 more days. Colonies were stained with crystal violet and counted as described above. The experiments were carried out in triplicates and included non-targeting siRNA control.

\section{Western blot analysis}

Preparation of cell lysates and analysis of treatmentinduced changes in the protein level were performed, as previously described [52]. Treatment (radiation and addition of drugs) was performed 48 hours post-plating. Protein content was determined with a bicinchoninic acid reagent (Bio-Rad, Hercules, CA), and equal loading was verified by comparing the levels of $\beta$-actin or by measuring the absorbance at $520 \mathrm{~nm}$ of Ponceau $\mathrm{S}$ (Sigma, St-Louis, MO), which was extracted with a phosphate buffer $\left(2.67 \mathrm{mM} \mathrm{KCl}, 1.47 \mathrm{mM} \mathrm{KH}_{2} \mathrm{PO}_{4}, 8.1\right.$ $\mathrm{mM} \mathrm{Na}_{2} \mathrm{HPO}_{4}$, and $1.125 \mathrm{M} \mathrm{NaCl}$ ) from individual strips of a twin run [51, 52]. Rabbit anti-MTH1 antibodies (NB100-109) and HRP-coupled goat anti-rabbit IgG were obtained from Novous Biologicals (Littlton CO) and Jackson Immunoresearch Laboratories (West Grove, PA), respectively. rabbit anti- $\gamma \mathrm{h} 2 \mathrm{AX}$, anti-RAD51 and anti-p21 were from Cell Signaling Technology (Danvers, MA) and rabbit-anti $\beta$-actin was purchased from abcam (Cambridge, UK). Blots were exposed to X-ray film for chemiluminescence, following treatment with a West Pico ECL reagent (Thermo Scientific Rockford, IL). Values for the integrated light density of autoradiograms were obtained with Image J NIH software and were employed for the determination of treatment-induced changes in protein levels.

\section{Detection of cellular ROS}

Evaluation of treatment-induced changes in cellular level of ROS was performed by employing CM$\mathrm{H}_{2}$ DCFDA as described by Giribaldi et al. (30). Cells were collected with $0.04 \%$ crystallized trypsin in Hank's balanced salt solution (HBSS). After washing with HBSS the cells were incubated with freshly prepared $2 \mu \mathrm{M}$ CM$\mathrm{H}_{2}$ DCFDA for 15 minutes in $37^{\circ} \mathrm{C}$, washed with HBSS and suspended in HBSS containing $2 \%$ FBS. Live cells $(\sim 90 \%$ of the population) were gated by forward and side scatter and green fluorescence emission $(520 \mathrm{~nm})$ from cells illuminated with $492 \mathrm{~nm}$ excitation light was measured by fluorescence-activated sorting (FACS) on a Navios flow cytometer (Beckman Coulter) and analyzed using Kaluza analysis software. A minimum of 20,000 cells were acquired for each sample. Staining with 7-aminoactinomycin D (7AAD, eBiosciences, San Diego, CA) verified that the percentage of dead cells within the gated population did not exceed $3 \%$. The data show the distribution of the cells according to their FL1 fluorescence intensities.

\section{The comet assay}

The comet assay was performed with the hOGG1 FLARE $^{\mathrm{TM}}$ Assay Kit according to the manufacturer's instructions with slight modifications. The cells were removed by trypsinization with $0.04 \%$ crystallized trypsin in HBSS, washed with cold PBS, embedded in agar and layered over the slides. Following incubation with lysis buffer, enzyme reaction buffer and treatment with hOGG1, the cells were further incubated in alkali solution and then subjected to electrophoresis at $21 \mathrm{~V}$ for 18 minutes. The cells were stained with $1 \mathrm{xSYBR}$ gold and viewed in fluorescent Nikon Eclipse Ti microscope equipped with Nikon Intenslight C-HHGFI camera. Two independent experments were conducted and 100 cells were scored in each sample from two separate experiments. The DNA tails were categorized as either long medium or none. Comets were defined as "long" when their length approximated the diameter of the nucleus from which they originated. 


\section{Wound-healing assay}

Cells were seeded into 6-well dishes and grown for 48 hours to $80 \%$ confluence. At that time, either TH588 or the vehicle was added to the cells. Four hours later, the bottom of the well was scratched with a perpendicularly placed $1 \mathrm{ml}$ pipette tip. Floating cells were removed, and fresh medium containing either TH588 or the vehicle was added to the wells. Photomicrographs of the wounded monolayers were obtained with an EVOS $^{\circledR}$ FL inverted microscope with a 10x objective at time 0 and every 24 hours thereafter. The width of the scratch was measured by employing the Image $J$ program at 10 different points along the scratch at time 0 and 4 days later at the end of the experiment. It was divided by two to obtain the distance travelled by the cells.

\section{Matrigel invasion assay}

The invasion assay was performed essentially as described by Li et al. [54] The cells were plated in serumfree media onto Matrigel-coated chambers $\left(\mathrm{Nunc}^{\circledR}\right.$, Denmark) and placed into wells containing media that was supplemented with $0.5 \%$ FBS. Either TH588 or DMSO was added to the inserted chambers. Following an incubation of 36 hours, the cells from the upper chambers were removed, and the invading cells at the bottom of the filter were stained with crystal violet. Photomicrographs were taken, as described above, for the migration assay, and the cells in each picture were counted with the Image J program. The assay was performed in duplicate, and a total of five randomly chosen fields were counted for each sample.

\section{Statistical analysis}

The significance of the differences between the experimental groups in clonogenic survival was verified by employing the unpaired Student $t$ test. $\mathrm{P}<0.05$ was considered statistically significant.

\section{Abbreviations}

CI - Combination index

DIPG - Diffuse intrinsic pontine glioma

HBSS - Hanks balanced salt solution

HDACi - Histone deacetylase inhibitor

MTH1- Human MutT homolog 1

OGG1- 8-Oxoguanine DNA glycosylase

8-Oxo-dGTP- 8-Oxo-2'-deoxyguanosine-5'-

Triphosphate

ROS - Reactive oxygen species

PARPi - Inhibitor of Poly [ADP-ribose] polymerase 1

\section{Author contributions}

Michal Yalon-Oren, Amos Toren, and Shoshana Paglin designed and supervised the studies and wrote the paper; Ziv
Versano designed and performed experiments and wrote the paper; Eytan Shany, Shany Freedman, Liron Tuval-Kochen and Moshe Leitner designed and performed experiments.

\section{CONFLICTS OF INTEREST}

The authors declare that they have no competing interest.

\section{FUNDING}

This study was supported by funds from The Sheba Medical Center.

\section{REFERENCES}

1. Stupp R, Hegi ME, Gilbert MR, Chakravarti A. Chemoradiotherapy in malignant glioma: standard of care and future directions. J Clin Oncol. 2007; 25: 4127-36.

2. Perkins SM, Rubin JB, Leonard JR, Smyth MD, El Naqa I, Michalski JM, Simpson JR, Limbrick DL, Park TS, Mansur DB. Glioblastoma in children: a single-institution experience. Int J Radiat Oncol Biol Phys. 2011; 80: 1117-21.

3. Yang T, Temkin N, Barber J, Geyer JR, Leary S, Browd $\mathrm{S}$, Ojemann JG, Ellenbogen RG. Gross total resection correlates with long-term survival in pediatric patients with glioblastoma. World Neurosurg. 2013; 79: 537-44.

4. Cohen KJ, Pollack IF, Zhou T, Buxton A, Holmes EJ, Burger PC, Brat DJ, Rosenblum MK, Hamilton RL, Lavey RS, Heideman RL. Temozolomide in the treatment of highgrade gliomas in children: a report from the Children's Oncology Group. Neuro Oncol. 2011; 13: 317-23.

5. Cohen KJ, Heideman RL, Zhou T, Holmes EJ, Lavey RS, Bouffet E, Pollack IF. Temozolomide in the treatment of children with newly diagnosed diffuse intrinsic pontine gliomas: a report from the Children's Oncology Group. Neuro Oncol. 2011; 13: 410-6.

6. Sturm D, Bender S, Jones DT, Lichter P, Grill J, Becher O, Hawkins C, Majewski J, Jones C, Costello JF, Iavarone A, Aldape K, Brennan CW, et al. Paediatric and adult glioblastoma: multiform (epi)genomic culprits emerge. Nat Rev Cancer. 2014; 14: 92-107.

7. Buczkowicz P, Hoeman C, Rakopoulos P, Pajovic S, Letourneau L, Dzamba M, Morrison A, Lewis P, Bouffet E, Bartels U, Zuccaro J, Agnihotri S, Ryall S, et al. Genomic analysis of diffuse intrinsic pontine gliomas identifies three molecular subgroups and recurrent activating ACVR1 mutations. Nat Genet. 2014; 46: 451-6.

8. Bender S, Tang Y, Lindroth AM, Hovestadt V, Jones DT, Kool M, Zapatka M, Northcott PA, Sturm D, Wang W, Radlwimmer B, Hojfeldt JW, Truffaux N, et al. Reduced H3K27me3 and DNA hypomethylation are major drivers of gene expression in $\mathrm{K} 27 \mathrm{M}$ mutant pediatric high-grade gliomas. Cancer Cell. 2013; 24: 660-72. 
9. Nakata S, Nobusawa S, Yamazaki T, Osawa T, Horiguchi K, Hashiba Y, Yaoita H, Matsumura N, Ikota H, Hirato J, Yoshimoto Y, Yokoo H. Histone H3 K27M mutations in adult cerebellar high-grade gliomas. Brain Tumor Pathol. 2017; 34: 113-9.

10. Braunstein S, Raleigh D, Bindra R, Mueller S, HaasKogan D. Pediatric high-grade glioma: current molecular landscape and therapeutic approaches. J Neurooncol. 2017; 134: 541-549.

11. Meyronet D, Esteban-Mader M, Bonnet C, Joly MO, UroCoste E, Amiel-Benouaich A, Forest F, Rousselot-Denis C, Burel-Vandenbos F, Bourg V, Guyotat J, Fenouil T, Jouvet A, et al. Characteristics of H3 K27M-mutant gliomas in adults. Neuro Oncol. 2017; 19: 1127-34.

12. Kallappagoudar S, Yadav RK, Lowe BR, Partridge JF. Histone H3 mutations--a special role for H3.3 in tumorigenesis? Chromosoma. 2015; 124: 177-89.

13. Bjerke L, Mackay A, Nandhabalan M, Burford A, Jury A, Popov S, Bax DA, Carvalho D, Taylor KR, Vinci M, Bajrami I, McGonnell IM, Lord CJ, et al. Histone H3.3. mutations drive pediatric glioblastoma through upregulation of MYCN. Cancer Discov. 2013; 3: 512-9.

14. Piunti A, Hashizume R, Morgan MA, Bartom ET, Horbinski CM, Marshall SA, Rendleman EJ, Ma Q, Takahashi YH, Woodfin AR, Misharin AV, Abshiru NA, Lulla RR, et al. Therapeutic targeting of polycomb and BET bromodomain proteins in diffuse intrinsic pontine gliomas. Nat Med. 2017; 23: 493-500.

15. Nagaraja S, Vitanza NA, Woo PJ, Taylor KR, Liu F, Zhang L, Li M, Meng W, Ponnuswami A, Sun W, Ma J, Hulleman E, Swigut T, et al. Transcriptional Dependencies in Diffuse Intrinsic Pontine Glioma. Cancer Cell. 2017; 31: 635-52.

16. Funato K, Major T, Lewis PW, Allis CD, Tabar V. Use of human embryonic stem cells to model pediatric gliomas with H3.3K27M histone mutation. Science. 2014; 346: 1529-33.

17. Grasso CS, Tang Y, Truffaux N, Berlow NE, Liu L, Debily MA, Quist MJ, Davis LE, Huang EC, Woo PJ, Ponnuswami A, Chen S, Johung TB, et al. Functionally defined therapeutic targets in diffuse intrinsic pontine glioma. Nat Med. 2015; 21: 555-9.

18. van Vuurden DG, Hulleman E, Meijer OL, Wedekind LE, Kool M, Witt H, Vandertop PW, Wurdinger T, Noske DP, Kaspers GJ, Cloos J. PARP inhibition sensitizes childhood high grade glioma, medulloblastoma and ependymoma to radiation. Oncotarget. 2011; 2: 984-96. https://doi. org/10.18632/oncotarget.362.

19. Ha K, Fiskus W, Choi DS, Bhaskara S, Cerchietti L, Devaraj SG, Shah B, Sharma S, Chang JC, Melnick AM, Hiebert $\mathrm{S}$, Bhalla KN. Histone deacetylase inhibitor treatment induces 'BRCAness' and synergistic lethality with PARP inhibitor and cisplatin against human triple negative breast cancer cells. Oncotarget. 2014; 5: 5637-50. https://doi. org/10.18632/oncotarget.2154.
20. Yalon M, Tuval-Kochen L, Castel D, Moshe I, Mazal I, Cohen O, Avivi C, Rosenblatt K, Aviel-Ronen S, Schiby G, Yahalom J, Amariglio N, Pfeffer R, et al. Overcoming Resistance of Cancer Cells to PARP-1 Inhibitors with Three Different Drug Combinations. PLoS One. 2016; 11: e0155711.

21. Chao OS, Goodman OB Jr. Synergistic loss of prostate cancer cell viability by coinhibition of HDAC and PARP. Mol Cancer Res. 2014; 12: 1755-66.

22. Gaymes TJ, Shall S, MacPherson LJ, Twine NA, Lea NC, Farzaneh F, Mufti GJ. Inhibitors of poly ADP-ribose polymerase (PARP) induce apoptosis of myeloid leukemic cells: potential for therapy of myeloid leukemia and myelodysplastic syndromes. Haematologica. 2009; 94: 638-46.

23. Leach JK, Van Tuyle G, Lin PS, Schmidt-Ullrich R, Mikkelsen RB. Ionizing radiation-induced, mitochondriadependent generation of reactive oxygen/nitrogen. Cancer Res. 2001; 61: 3894-901.

24. Conklin KA. Chemotherapy-associated oxidative stress: impact on chemotherapeutic effectiveness. Integr Cancer Ther. 2004; 3: 294-300.

25. Leone A, Roca MS, Ciardiello C, Terranova-Barberio M, Vitagliano C, Ciliberto G, Mancini R, Di Gennaro E, Bruzzese F, Budillon A. Vorinostat synergizes with EGFR inhibitors in NSCLC cells by increasing ROS via up-regulation of the major mitochondrial porin VDAC1 and modulation of the c-Myc-NRF2-KEAP1 pathway. Free Radic Biol Med. 2015; 89: 287-99.

26. Nakabeppu Y. Cellular levels of 8-oxoguanine in either DNA or the nucleotide pool play pivotal roles in carcinogenesis and survival of cancer cells. Int J Mol Sci. 2014; 15: 12543-57.

27. Patel A, Burton DG, Halvorsen K, Balkan W, Reiner T, Perez-Stable C, Cohen A, Munoz A, Giribaldi MG, Singh S, Robbins DJ, Nguyen DM, Rai P. MutT Homolog 1 (MTH1) maintains multiple KRAS-driven pro-malignant pathways. Oncogene. 2015; 34: 2586-96.

28. Rudd SG, Valerie NCK, Helleday T. Pathways controlling dNTP pools to maintain genome stability. DNA Repair (Amst). 2016; 44: 193-204.

29. Rai P. Human Mut T Homolog 1 (MTH1): a roadblock for the tumor-suppressive effects of oncogenic RAS-induced ROS. Small GTPases. 2012; 3: 120-5.

30. Giribaldi MG, Munoz A, Halvorsen K, Patel A, Rai P. MTH1 expression is required for effective transformation by oncogenic HRAS. Oncotarget. 2015; 6: 11519-29. https://doi.org/10.18632/oncotarget.3447.

31. Konstantinopoulos PA, Wilson AJ, Saskowski J, Wass E, Khabele D. Suberoylanilide hydroxamic acid (SAHA) enhances olaparib activity by targeting homologous recombination DNA repair in ovarian cancer. Gynecol Oncol. 2014; 133: 599-606. 
32. Haghdoost S, Sjolander L, Czene S, Harms-Ringdahl M. The nucleotide pool is a significant target for oxidative stress. Free Radic Biol Med. 2006; 41: 620-6.

33. Bialkowski K, Szpila A, Kasprzak KS. Up-regulation of 8-oxo-dGTPase activity of MTH1 protein in the brain, testes and kidneys of mice exposed to (137)Cs gamma radiation. Radiat Res. 2009; 172: 187-97.

34. Petruccelli LA, Dupere-Richer D, Pettersson F, Retrouvey $\mathrm{H}$, Skoulikas S, Miller WH Jr. Vorinostat induces reactive oxygen species and DNA damage in acute myeloid leukemia cells. PLoS One. 2011; 6: e20987.

35. Hocsak E, Szabo V, Kalman N, Antus C, Cseh A, Sumegi K, Eros K, Hegedus Z, Gallyas F Jr, Sumegi B, Racz B. PARP inhibition protects mitochondria and reduces ROS production via PARP-1-ATF4-MKP-1-MAPK retrograde pathway. Free Radic Biol Med. 2017; 108: 770-84.

36. Coskun E, Jaruga P, Jemth AS, Loseva O, Scanlan LD, Tona A, Lowenthal MS, Helleday T, Dizdaroglu M. Addiction to MTH1 protein results in intense expression in human breast cancer tissue as measured by liquid chromatographyisotope-dilution tandem mass spectrometry. DNA Repair (Amst). 2015; 33: 101-10.

37. Kennedy CH, Cueto R, Belinsky SA, Lechner JF, Pryor WA. Overexpression of hMTH1 mRNA: a molecular marker of oxidative stress in lung cancer cells. FEBS Lett. 1998; 429: 17-20.

38. Kajitani K, Yamaguchi H, Dan Y, Furuichi M, Kang D, Nakabeppu Y. MTH1, an oxidized purine nucleoside triphosphatase, suppresses the accumulation of oxidative damage of nucleic acids in the hippocampal microglia during kainate-induced excitotoxicity. J Neurosci. 2006; 26: $1688-98$.

39. Gad H, Koolmeister T, Jemth AS, Eshtad S, Jacques SA, Strom CE, Svensson LM, Schultz N, Lundback T, Einarsdottir BO, Saleh A, Gokturk C, Baranczewski P, et al. MTH1 inhibition eradicates cancer by preventing sanitation of the dNTP pool. Nature. 2014; 508: 215-21.

40. Kumar CC, Prorock-Rogers C, Kelly J, Dong Z, Lin JJ, Armstrong L, Kung HF, Weber MJ, Afonso A. SCH 51344 inhibits ras transformation by a novel mechanism. Cancer Res. 1995; 55: 5106-17.

41. Huber KV, Salah E, Radic B, Gridling M, Elkins JM, Stukalov A, Jemth AS, Gokturk C, Sanjiv K, Stromberg K, Pham T, Berglund UW, Colinge J, et al. Stereospecific targeting of MTH1 by (S)-crizotinib as an anticancer strategy. Nature. 2014; 508: 222-7.

42. Bax DA, Little SE, Gaspar N, Perryman L, Marshall L, Viana-Pereira M, Jones TA, Williams RD, Grigoriadis A, Vassal G, Workman P, Sheer D, Reis RM, et al. Molecular and phenotypic characterisation of paediatric glioma cell lines as models for preclinical drug development. PLoS One. 2009; 4: e5209.
43. See WL, Tan IL, Mukherjee J, Nicolaides T, Pieper RO. Sensitivity of glioblastomas to clinically available MEK inhibitors is defined by neurofibromin 1 deficiency. Cancer Res. 2012; 72: 3350-9.

44. Pudelko L, Rouhi P, Sanjiv K, Gad H, Kalderen C, Hoglund A, Squatrito M, Schuhmacher AJ, Edwards S, Hagerstrand D, Berglund UW, Helleday T, Brautigam L. Glioblastoma and glioblastoma stem cells are dependent on functional MTH1. Oncotarget. 2017; 8: 84671-84. https://doi. org/10.18632/oncotarget.19404.

45. Sharma A, Singh K, Almasan A. Histone H2AX phosphorylation: a marker for DNA damage. Methods Mol Biol. 2012; 920: 613-26.

46. Smith CC, O’Donovan MR, Martin EA. hOGG1 recognizes oxidative damage using the comet assay with greater specificity than FPG or ENDOIII. Mutagenesis. 2006; 21: 185-90.

47. Samaranayake GJ, Huynh M, Rai P. MTH1 as a Chemotherapeutic Target: The Elephant in the Room. Cancers (Basel). 2017; 9.

48. Ke Y, Lv Z, Yang X, Zhang J, Huang J, Wu S, Li YR. Compensatory effects of hOGG1 for hMTH1 in oxidative DNA damage caused by hydrogen peroxide. Toxicol Lett. 2014; 230: 62-8.

49. Warpman Berglund U, Sanjiv K, Gad H, Kalderen C, Koolmeister T, Pham T, Gokturk C, Jafari R, Maddalo G, Seashore-Ludlow B, Chernobrovkin A, Manoilov A, Pateras IS, et al. Validation and development of MTH1 inhibitors for treatment of cancer. Ann Oncol. 2016; 27: 2275-83.

50. Aristizabal Prada ET, Orth M, Nolting S, Spottl G, Maurer J, Auernhammer C. The MTH1 inhibitor TH588 demonstrates anti-tumoral effects alone and in combination with everolimus, 5-FU and gamma-irradiation in neuroendocrine tumor cells. PLoS One. 2017; 12: e0178375.

51. Paglin S, Lee NY, Nakar C, Fitzgerald M, Plotkin J, Deuel B, Hackett N, McMahill M, Sphicas E, Lampen N, Yahalom J. Rapamycin-sensitive pathway regulates mitochondrial membrane potential, autophagy, and survival in irradiated MCF-7 cells. Cancer Res. 2005; 65: 11061-70.

52. Tuval-Kochen L, Paglin S, Keshet G, Lerenthal Y, Nakar C, Golani T, Toren A, Yahalom J, Pfeffer R, Lawrence Y. Eukaryotic initiation factor 2alpha--a downstream effector of mammalian target of rapamycin--modulates DNA repair and cancer response to treatment. PLoS One. 2013; 8: e77260.

53. Chou TC. Drug combination studies and their synergy quantification using the Chou-Talalay method. Cancer Res. 2010; 70: 440-6.

54. Li Y, Huang Y, Qi Z, Sun T, Zhou Y. MiR-338-5p Promotes Glioma Cell Invasion by Regulating TSHZ3 and MMP2. Cell Mol Neurobiol. 2017; 38: 669-677. 